\title{
The doctor's role in the prevention of accidents
}

It has been said elsewhere that doctors working in the field of child health should be more aware than they appear to be at present of the part that they can play in preventing accidents-which are the most important problem in the health of children after the first year of life. Yet many doctors do not know what they can do in this field; this paper is an attempt to detail the different approaches that might be made by doctors in the various branches of the health services for children.

Two general aspects of accident prevention work need to be stated here. First, that almost all of it involves liaison with other professions or disciplines. This is in contrast with most other paediatric preventive work-for example, immunisationswhere the responsibility lies almost entirely within the province of the health services and which is carried out by health workers. But it is obvious that the prevention of road accidents, for example, involves many disciplines other than health, and therefore doctors must be prepared to work in close collaboration with others. The second general point is that an accident or injury involves a child coming into contact with a harmful 'agent' under a defined set of circumstances-physical, psychological, and social. Accident prevention work can therefore be directed towards one or more of these areas: education of the child or of those responsible for him, a reduction in the potential for harm of the 'agent', and a change in the environmental circumstances under which the accident or injury took place. A useful general question to ask oneself is 'As this particular child was injured by this particular object in this particular way under this set of circumstances, how can I prevent another child being injured in the same way and under the same circumstances?'

Paediatricians and other child health doctors are in direct contact with the child and his parent and therefore much of the emphasis of the role of doctors actually dealing with the injured child will be epidemiological and factual: in finding out the details of the factors involved and in passing on this information to others who may be in a position to take preventive action. Other doctors-for example, clinical medical officers and general practitioners, who may not see the child at the actual time of the injury, may find that their work is more educational either by direct discussion with mothers in clinics or surgeries or by encouraging health visitors in accident prevention work. Health visitors have a prime role in this whole field and their function has been the subject of a special study and report by Ms Pam Laidman of the Child Accident Prevention Trust ${ }^{1}$ and will therefore not be discussed further here.

More detailed suggestions of the parts that might be played by specific doctors are now given.

\section{Community paediatricians}

The role of the community paediatrician should primarily be to study the epidemiology of accidents in his area: how many and of what type, how and where they occur and to whom. Information on these aspects is essential if a local accident prevention campaign is to be mounted: not only do local problems need to be identified to make the campaign as relevant as possible, but the continued collection of data is needed to monitor the effectiveness of the campaign.

Collection of satisfactory data will not necessarily be easy, as most accident and emergency departments do not collect the type of information that is really needed for accident prevention work, and the community physicians first task may well be to improve the data collection system. It must be

Table Organisations or people who may collect data at a local level on accidents to children

\section{Health aspects}

Hospital inpatient enquiry

Hospital activity analysis

Accident and emergency department

General practitioner

\section{Road accidents}

Police

Road safety officer

Highway or engineers department

Home accidents

Home accident surveillance system

Home safety officer

Trading standards officer

Others

Environmental health officer

Education authority

Health and safety executive

Recreation and leisure department 
remembered too that other disciplines collect data of their own (table). This emphasises the multidisciplinary nature of accident prevention: police, road safety officers, teachers, home safety officers, health education officers, trading standards officers as well as members of the health professions, particularly health visitors, may all be involved at a local level. It may well be that in due course the community paediatrician may call together a local child accident prevention group involving health authority and local authority officials as well as voluntary groups. $\mathrm{He}$ would then be able to present information on the size and nature of the problem and in this way he is likely to be the intermediary between the health services and the other agencies involved.

If there is no community paediatrician in the district then this epidemiological and coordinating role is likely to be taken on by the district medical officer in conjunction with the senior medical officer (child health), or whoever is designated as being responsible for the community child health services.

\section{Clinical medical officer (community health doctors, child health doctors)}

The role of the clinical medical officer would seem to be a dual one. Firstly, to take part in the education of mothers either in face to face discussions in the clinic or by talking to parent groups, and to work with the health visitors associated with the clinic. Secondly, to receive information from health visitors and mothers about safety matters-toys or other products considered to be unsafe, road crossings or toddler playgrounds that seem to present an undue hazard. This information can then be passed on to the appropriate local authority or to the person in the health authority concerned by the community paediatrician. Doctors involved with schools should ensure that accidents and their prevention are included in the health education programme of their schools.

\section{General practitioner}

Although general practitioners do not come under the administrative wing of the local health authority, they are included here as they are obviously involved in the health care of children. They deal with many minor injuries to children, and, particularly in rural areas, with major injuries too. In dealing with these their role is similar to that of hospital doctors discussed below, but in addition they play a part similar to the clinical medical officers in educating parents. In the course of their home visits they may be able to point out hazardous practices or features of the house such as dangerous glass doors, bannisters or balcony railings, trailing kettle flexes, etc, and thus they have the potential to be able to reduce home accidents quite considerably. Another example of where the general practitioner can exert his influence is in increasing the use of child safety seats in cars.

\section{Hospital doctor}

The joint memorandum on the managment of children in accident and emergency departments issued jointly by the British Paediatric Association and the Casualty Surgeon's Association, ${ }^{2}$ suggests that a consultant paediatrician should be designated as having a particular relationship with the accident and emergency department in respect of children attending there, and it would seem sensible for this consultant also to be concerned with aspects relating to accident prevention.

In contrast with the epidemiological role of the community paediatrician the hospital doctor's role will be more concerned with the analysis needed to uncover the causes of the accident. He, his staff, or the doctors in accident and emergency must be prepared to go into detail about the agent and the environmental circumstances of the accident: was the child restrained and in which seat was he sitting in the car accident? Was the child cyclist wearing a cycle helmet? Which particular piece of equipment and in which playground did the child fall from? Was the school playground supervised at the time? Were the mother's tablets that the toddler got hold of in a child resistant container, and if not had the mother taken them out of one or had the pharmacist not dispensed them in a child resistant containerand if not, why not? How did the child manage to climb up the balcony railings before he fell overwere there horizontal bars that he could climb? Was 9 the lollipop lady on duty at the time or was she off sick? What was the make of the high chair that the child managed to unbalance? These and similar questions need to be answered and the information $\Omega$ passed either through the community paediatrician $N$ or direct to the local authority officer concerned. It can then be collated together with information from other sources so that appropriate preventive action can be taken in respect of consumer product safety, $\frac{\widetilde{\Phi}}{\Phi}$ the safety of playground equipment, the placing of $\stackrel{0}{\rightarrow}$ road crossings, and in very many other ways.

\section{Conclusion}

Only when child health doctors assemble the in- 
formation of the accidents and injuries that they deal with and begin to work with other disciplines in the field of prevention will a real impact be made on the reduction in the deaths and injuries to children from accidents.

\section{References}

1 Laidman $\mathrm{P}$. The health visitor's role in the prevention of accidents to children. London: Child Accident Prevention Trust. 1987.

See Special report p 318.
2 Children's Attendances at Accident and Emergency Departments. A Joint Statement by the British Paediatric Association, the British Association of Pacdiatric Surgeons, and the Casualty Surgeon's Association. London: British Paediatric Association, May 1987.

R H JACKSON Child Accident Prevention Trust, 28 Portland Place, London WIN 4DE 